\title{
Impact of Livelihood Empowerment against Poverty Programme in Ghana: The Case of Wa West District
}

\author{
Eugene Bongfudeme Gideon Bawelle (Corresponding author) \\ Curtin Business School, Curtin University \\ GPO Box U 1987, Perth Western, Australia \\ Tel: 61-426-966-212Ｅ-mail: bawelleeugene@gmail.com
}

Received: May 4, 2016 Accepted: June 16, 2016 Published: September 19, 2016

doi:10.5296/ijssr.v4i2.9415 URL: http://dx.doi.org/10.5296/ijssr.v4i2.9415

\begin{abstract}
It still remains an unanswered puzzle, why poverty in the three northern regions of Ghana remains very high in the midst of abundant resources and several policy interventions. The purpose of this study is to ascertain the extent to which the Livelihood Empowerment Against Poverty (LEAP) has improved welfare and reduced poverty in the Wa West District of Ghana. Arguing through the lens of the rights-based theoretical perspective, the study employed the difference-in-difference analytical technique to compare the extent to which poverty in the district has been lessened among beneficiaries of the LEAP programme against non-beneficiaries. The results show that the LEAP programme had a positive impact on food security as LEAP beneficiaries were more satisfied with their food consumption as compared to non-beneficiaries. Also there was a significant difference between the percentages of LEAP beneficiaries enrolled onto the NHIS as compared to non-beneficiaries. On the effect of the LEAP programme on access to credit, the study reveals that there exists a significant difference between the beneficiary group and non-beneficiary group and that access to credit amongst the beneficiary group is significantly higher than the non-beneficiary group. The study finds no statistically significant relationship between the LEAP beneficiary group and the non-beneficiary group in terms of productive activities. However, low monthly cash transfers; irregular monthly payment, bureaucratic administrative procedures are some of the challenges hindering the success of the LEAP program in the Wa West district. Other policy implications are discussed.
\end{abstract}

Keywords: Livelihood Empowerment, Ghana, Poverty, LEAP, Rights based approach, entitlement approach 


\section{Introduction}

One of the two major trends that has considerably influenced the political reality of many developing nations is poverty reduction. This became a predominant goal of development policy and had been profoundly influenced by stabilization and Structural Adjustment Programmes until the early 1990s. Stabilization and structural adjustment measures, usually recognized as the "Washington Consensus", had more and more been criticized because they turned out to be worsening poverty and inequality in some countries (Khor, 2003). It is as a result of this that researchers and policymakers globally engaged in a broad debate about the design and execution of poverty reduction strategies. Concerted global effort at reducing poverty and inequality over the last couple of decades therefore, has led to the establishment of social protection programmes. This campaign has seen widespread responsiveness in developing countries. Many governments in the developing world have resorted to social protection as a means of ending chronic poverty. Conditional and Social Cash Transfer Programmes have prominently featured in many annual budgets and development policies in Third World Countries. Cornia (2014) indicates that some national governments among developing countries have on their own or collaboratively with donor and development assistance began to embrace the idea of offering social protection packages particularly in the form of social cash transfers for the very deprived and weak in society.

Despite numerous global efforts targeted at reducing its impact, the phenomenon continues to persist with profound manifestations in the lives of low income earners and weak groups in the developing countries (Fernald, 2013). It is agreeable that even though social interventions over the years may have resulted in some success, many more as the case would be, have either made people more vulnerable or chronically dependent (Kaldor, 1955).

The paradox of Ghana's rich natural and human resources coupled with a stable democracy and her high level of poverty is unfathomable. It is mind baffling that a country which has gold, bauxite, manganese, cocoa and very recently oil in commercial quantities would rank 78th out of 157 poorest countries of the world. According to the Ghana Statistical Survey (2014), about a quarter of Ghanaians are poor whilst under a tenth of the population is in extreme poverty. The dynamics of poverty in its entirety is very much prevalent especially among rural communities and more chronic in its regional distribution (GSS, 2014). Several social policy interventions in the past and present have sought to address the pervasive incidence of poverty in Ghana. The Capitation Grant, School Feeding Programme, National Health Insurance Scheme and many more have sought to bridge the gap of disparity between the poor and rich.

At independence in 1957 the government offered free health care services to its populace which was exclusively financed from tax revenues. However, the scheme was not viable because the government shifted its focus to other sectors of the economy (Sulzbach, Garshong, \& Banahene, 2005). From that time on different nominal fees were announced. Later on the cash and carry system was introduced with the provision of medical services solely by a direct payment (Sulzbach et al., 2005). By recognizing that growth and normal development interventions are not adequate at reducing poverty and economic shocks among 
the people, the State decided on two strategies to improve the situation of the weak groups, namely the National Social Protection Strategy (NSPS) and the Ghana Growth and Poverty Reduction Strategy (GPRS). Ghana's National Social Protection Strategy is partially motivated by the fact that growth alone is not adequate for the fight against poverty. This policy document contained different measures aimed at reducing poverty. It will also lead to the achievement of the first millennium development goal of the United Nations (Abebrese, 2011). The government introduced the National Health Insurance Scheme (NHIS) so as to provide basic healthcare services through mutual and private health insurance schemes. It was designed and introduced to supplant the cash and carry system which required the people to pay money in cash when they seek medical care (NHIS, 2011). To increase school enrollment, attendance and retention, reduce hunger and malnutrition and boost domestic food production the State introduced the Ghana school feeding programme in 2005. It is an initiative of the Comprehensive Africa Agricultural Development Programme (CAADP) pillar 3 with assistance from the New Partnership for Africa's Development (NEPAD). The LEAP programme however, is the flagship programme of Ghana's National Social Policy Strategy (NSPS) designed to reduce poverty and provide a better life for the Ghanaian population. It contains financial support for orphan/ vulnerable children, people over 65 years and people with disabilities. The implementing agency is the Department of Social Welfare (DSW). It was implemented by mid-2009 and in 2010 it covered 45,000 households (Abebrese, 2011). Apart from providing cash, LEAP promotes an 'integrated social development approach' aimed at linking beneficiaries with complementary services. For example, the Ministry of Employment and Social Welfare signed a memorandum of understanding with the Health, Education and Agriculture Ministries to provide free access to the NHIS, free school uniforms and access to agricultural support. There was evidence of the linkage of LEAP to micro-credit through the Ministry of Women and Children's Affairs (Essuman \& Bosumtwi-Sam, 2013).

One of the poorest regions in Ghana is the Savannah ecological zone and many have questioned whether the introduction of this programme has had any impact on the poor in this region. The Wa West district (which also benefits from the LEAP) is part of this area, where, according to the Fiszbein, Schady, and Ferreira (2009), the incidence of poverty has increased by 0.9 million between 1992 and 2006. This study will address two important research questions.

\section{Research Questions}

1) What is the effect of direct cash transfer on welfare and poverty reduction in Wa West?

2) What are the challenges of the LAEP programme in the Wa West District?

\section{Rights-Based Approach as the Theoretical Framework}

A rights-based development approach to development is relatively new in development literature. It places emphasis on the accomplishment of the minimum conditions for living with dignity. Rights-Based framework is defined on the basis of the legal, socioeconomic or political perspectives. These definitions also are largely by the diverse national and 
international legal standards that identify and promote human rights (Kapur \& Duvvury, 2006). It must be indicated that there are shared elements across the varying academic and legal conceptual frameworks (UNDP, 2003). A rights-based approach is a conceptual framework for the process of human development that is normatively premised on international human rights standards and operationally directed to promoting and protecting human rights. A human rights approach adds value because it offers a normative framework of obligations that has legal power to render governments accountable (Nyamu-Musembi \& Cornwall, 2004). Rights-based approach emphasizes on the robust link among good governance, poverty reduction and livelihood empowerment (Yaro,2004). The FAO (2004) has indicated that a rights-based approach to food security maintains that people have an ultimate right to be hunger-free. It sees the beneficiaries of development not simply as passive beneficiaries, but as active stakeholders. It also postulates that the state has the definitive responsibility of making sure that people have access to both physical and economic resources. Food should not be used as a political and economic bargaining tool.

The International Covenant on Economic, Social and Cultural Rights, which came into being in 1976, gave national governments three responsibilities: obligations to respect, obligations to protect and obligations to fulfill (UNDP, 2003). According to Kent (2015), the right to adequate food is accomplished when every human being, either acting alone or in a community of people, have the economic wherewithal to food accessibility. Adequate food, he continues, means enough food in acceptable quantity and quality, as society expects. A rights-based approach presents another opportunity of answering the food and nutrition uncertainty conundrum; it places emphasis on access to food for everyone and also requires various governments to design adequate food policies and programmes which will sufficiently give protection to the poor. The FAO (2004) adopted the "Voluntary Guidelines to support the progressive realization of the right to adequate food in the context of national food security", generally known as the Voluntary Guidelines. These guidelines provide direction to governments to help in the realization of food adequacy rights. The definition used for the right to adequate food is not only about food accessibility but also the accessibility of productive resources so that people can produce and acquire their own food. The right-based approach has not been without challenges. Yaro (2004) identified the problem of magnitude to which social, economic, and cultural rights are applied to unsuitable policies and the dilemma in allocating rights in societies with conflicting interest groups.

\section{The Rise of Social Cash Transfer model in Poverty Reduction}

Existing literature on social cash transfer suggest that social cash transfers have the ability to enhance pro-poor growth in a number of ways notably by presenting an efficient risk management tool, by aiding and supporting human capital development and by empowering poor households to lift themselves out of the seemingly chronic poverty trap. Such transfers can be universal or explicitly targeted at those identified (OECD, 2009; cited in (Joha, 2012). Some developing countries have made such provisions explicitly clear and have enshrined them in their constitutions by including rights to social protection, for instance, Bolsa Faḿlia in Brazil, Progressain Mexico have successfully established social entitlements systems which have considerably reduced the incidence of poverty and inequality over the 
last decade (Samson, 2006). Similar programmes such as these are gradually gaining popularity among governments in Africa like Kenya and Malawi. It is also widespread around the world, including developed economies such as in the city of New York (Currie \& Gahvari, 2007). The Government of Ghana is no exception and is following models from the success stories and best practices of these countries to implement the LEAP in order to tackle poverty. Several rationales have been advanced for the need to embark on social cash transfers as a means to promote pro-poor growth. According to the Organization for Economic Co-operation and Development (OECD) Report (2009), cash transfers provide an important risk management tool for the vulnerable poor at three levels: (1) reducing the poverty resulting from shocks such as natural disasters including drought, floods, and economic shocks, such as, sudden food price increases, (2) reducing vulnerability and (3) strengthening coping mechanisms. Social cash transfers can also reduce vulnerability by absorbing the effect of shocks on people's lives generally through the stimulation of general economic activity. Cash transfers also protect households by lessening the effects of shocks on productive assets (Joha, 2012). The transfer of cash to households reduces the level of risk because there is an assured minimum level of income to the household. This enables school enrolment for children from these poor households. It is also an avenue for the provision of nutritious food and access to health care. Vulnerable households can also engage in more risky ventures and stand the chance of higher returns in income, or attain human capital such as higher education so as to get better paying jobs. When the cash transfer is executed in a manner that is generally acceptable to the community and nation at large, it has the propensity to build social cohesion and a sense of citizenship, and reduce conflict (Arvind \& Devesh, 2003). A safe, secure and stable environmental condition is a prerequisite to encourage individuals and groups, to work and invest. The social pension in Mauritius for example was largely responsible for the social cohesion necessary to enable the movement from a susceptible mono-crop economy with high poverty rates into a high growth country with the lowest poverty rates in Africa (Arvind \& Devesh, 2003). The cash transfers gave farmers in Mauritius the opportunity to go into farming and to diversify their produce. This led to high yields and high incomes. The cost of not doing anything to protect the poor and weak is an enormous price because, it not only leads to chronic and social exclusion and or entrapment in a vicious poverty cycle, it also leads to a more disgruntled society. (Arvind \& Devesh, 2003)

A study by the Department for International Development (DFID), UK in Maharashtra, India in 2005 found that, farmers protected by the Employment Guarantee Scheme; invested in higher yielding varieties than farmers in neighbouring states (DFID, 2005). This was because they had extra funds to diversify their farm produce and enjoy high economies of scale as compared to those who did not receive such cash incentives. Despite the important role that cash transfers play in mitigating the incidence and frequency of poverty, it is argued, among some quarters, that it has the tendency to create a level of dependency thus not fostering any meaningful intended development (Kaldor, 1956). The author contends that if the status quo is maintained the rich will use their wealth to increase aggregate savings in the country and promote economic growth by creating employment for the poor. This, he argues, would eliminate the dependency that exists when hand-outs are given and people are not required to 
work for their income. Künnemann and Leonhard (2008) disagree with this assertion and contend that dependency from the State is not necessarily worse than being dependent on a husband, a rich relative or on begging the neighbours. Cash transfer is a matter of rights and beneficiaries are positioned to demand for these rights and not become beggars. They actually participate in the decision making process. A rights-based approach to social cash transfer creates an entitlement for beneficiaries that replace dependency with a reliable guarantee. A number of studies have revealed that beneficiaries of cash transfers seeking employment are more successful at it than do their counterparts in comparably poor households who do not have access to social cash grants (Williams, 2007). This is because they are able to set up small businesses and also take care of their children in school. Evidence of such impacts is found for Mexico and Brazil, and also more anecdotal evidence is found in Namibia, Zambia and Kenya (Barrientos, 2005). As a result of the enormous wealth of studies showing the success of cash transfer in poor countries, the World Bank (2001) and the Inter-American Development Bank are increasingly making loans to finance social transfer strategies across the globe (Samson, 2006).

\subsection{Evidence of the Impact of Cash Transfers}

There exists considerable evidence of the impact of cash transfers programmes. Some of the benefits of cash transfer include poverty alleviation, improvement in health, high educational and nutritional outcomes, growth in the economy, empowerment, especially for women, and a general social cohesion. Poverty alleviation and reduction in vulnerability however, remain the primary objectives of cash transfer programmes. This is because such transfers are expected to positively impact on the productive strategies and livelihoods of poor people. In the long term, the effects of cash transfer as evidence suggests, can help break the intergenerational transmission of poverty (Devereux \& Coll-Black, 2007). A lot of the evidence on the long term effects of cash transfer derives from the literature of one of the most evaluated programmes, Mexico's Progresa, later renamed Oportunidades). Evidence from these research studies indicate that partaking in the programme results in improvements in the productive capacity of poor households in the long term. The poverty gap, as a result of this cash transfer, reduced by $30 \%$ among beneficiaries after two years of operation; raised the height-for-age of beneficiary children by $1 \mathrm{~cm}$ after two years compared with a control group; and is also projected to raise the years of schooling among beneficiary children completing the education cycle by close to one additional year. The Bolsa Familia in Brazil also generated some understanding on the long term effects, including the prospect of cash transfers stimulating entrepreneurship amongst recipients (Fiszbein et al., 2009).

Evidence also abounds, that cash transfers have curtailed the incidence of poverty and its severity (i.e. the poverty gap) amongst most evaluated middle income country programmes. Studies across countries have consistently demonstrated evidence of positive impacts as per capita consumption has increased. Household data analysis shows that the marginal effect of non-contributory pension receipt within the household is to reduce the probability of poverty by $18 \%$ in Brazil and $12.5 \%$ in South Africa (Barrientos, 2005). Micro simulation modeling with latest household survey data approximates that the Progresa/ Oportunidades programme in Mexico has reduced the poverty gap by almost 20\%, from 8.5 to 6.8 (Fiszbein et al., 2009). 
The Child Support Grant in South Africa has also seen a reduction in the poverty gap by $47 \%$. Other research studies have also documented the extent to which cash transfer programmes operating at scale can help abridge income inequality.

In South Africa, the well-executed cash grant system is estimated to reduce the country's Gini coefficient by three percentage points. It also approximately doubles the national income share attributable to the poorest quintile. In Brazil, both the BPC (means-tested old age pension and disability grant programme) and Bolsa Familia cash transfer programmes were jointly responsible for $28 \%$ of the 2.7 percentage point reduction in the Gini coefficient, from 1995 - 2004, 7 \% from BPC and 21 \% from Bolsa Família (Samson et al., 2004). Cash transfers have helped to reduce the depth of poverty at the national level. In Brazil, poverty at the national level reduced from $9.8 \%$ to $9 \%$; the decline in Ecuador was from $7.0 \%$ to $6.1 \%$; from $6.6 \%$ to $6.0 \%$ in Jamaica and from $8.5 \%$ to $6.8 \%$ in Mexico. Evidence consistently corroborates that several cash transfer programmes have markedly improved nutritional levels and use of health care and educational services. As to whether this has translated into improved health or education status still remains unclear. In some cases, cash transfers have resulted in major improvements in final outcomes (e.g. in child growth). They have also played a role in the treatment and general wellbeing of people living with HIV and AIDS, as well as orphans and vulnerable children. Successfully executed cash transfer programmes can be seen as a complement to investments in the supply of indispensible public services, by connecting households and individuals to overcome financial barriers and to access services (such as transport) (Devereux \& Coll-Black, 2007).

One conclusion consistent with many research findings regarding the impact of cash transfer programmes is the fact that cash transfers have contributed immensely to reducing hunger and food insecurity. Irrespective of the form of transfer, recipient households average a considerably higher expenditure on food consumption. The impact of cash transfers on hunger has been most prominent in LICs where poverty is commonly more chronic. In these areas, many households who receive extra income are particularly likely to prioritize spending on improving the quantity and/or quality of food consumed. In Ethiopia, for example, the Productive Safety Net Programme has improved food security for 7.8 million people who hitherto depended on emergency relief. The programme, operating in 300 rural districts facing acute food shortage, "provides food or cash for work as well as unconditional cash transfers or food aid to those unable to participate in public works. Three-quarters of participants consumed higher quantity and quality of food compared to the previous year, and 60 percent had avoided selling off their productive assets to buy food" (Devereux \& Coll-Black, 2007). An appraisal of Malawi's Cash Transfer programme indicated that about $75 \%$ of the cash transfer was used to purchase groceries (Vincent \& Cull, 2009).

Studies show that in Nicaragua, children in households who received transfers from the RPS (a Conditional Cash Transfer (CCT) programme) experienced a reduction in malnutrition 1.7 times greater than the national trend after two years (Devereux \& Coll-Black, 2007). In Lesotho, $48 \%$ of old age pensioners on the "old age pension" reported that they never went hungry after being enrolled, as compared to $19 \%$ before (Vincent \& Cull, 2009). Most studies which sought to quantify the effect of cash transfers on hunger, nutrition or food security, 
identified a positive impact (Devereux \& Coll-Black, 2007). The literature shows evidence of the impact of cash transfer programmes on primary and secondary school enrolment. Receipt of a cash transfer (whether conditional or unconditional) can increase school enrolment by helping vulnerable households to conquer the cost barriers to schooling (fees, uniforms, books etc.) (Ribas, Soares, \& Hirata, 2008). Evidence from Malawi's social cash transfer programme indicates that targeting recipient households with children resulted in an increase in school enrolment of 5 percentage points among children aged 6-17. Targeting households which had orphans also generated an increase of 4.2 points (Handa \& Stewart, 2008). Participants in the Bolsa Família programme in Brazil are $20 \%$ less likely than comparable to children in non-participant households to have a one-day absence from school in any given month. Cash transfer recipients are $63 \%$ less likely to drop out of school and $24 \%$ more likely to advance an additional year (Ribas et al., 2008).

Cash transfers can increase reductions in morbidity and mortality. This is achieved through the 'demand side' by helping poorer families to overcome the economic impediments to access and use of health services. Available evidence from many studies in both LICs and MICs indicates a positive impact of cash transfers on the use of health care services. Most apparently, cash transfers increase the amount of money available for spending on health care services (DFID, 2005). In Lesotho, for example, $50 \%$ of recipients of pension allowance have increased their spending on health services since the implementation of the pension in 2005 (Samson, 2006). Preventative health services, as the evidence suggests for cash transfers, is generally stronger for children, and more limited for adults, even though there is increasing evidence for the contribution of transfers to maternal health (Devereux \& Coll-Black, 2007). The LEAP grant has an impact on the frequency of utilization of healthcare facilities. The LEAP grant enables access to and use of healthcare services for the poor and can therefore be considered as a major relieve. The fact that beneficiaries spend part of the grant in registering for health insurance or paying for health care related expenditures shows that the poor themselves appreciate the essence of the grant and thus invest it into safeguarding or minimising the financial barriers associated with the risk of ill health (Agbaam \& Dinbabo, 2014).

\section{Methodology}

In order to assess the extent to which the Livelihood Empowerment Against Poverty (LEAP) has improved welfare and alleviated poverty in the district, the study proceeded in two ways. In the first place, the study examined how direct cash transfer affects welfare and poverty reduction. The second part focused on the challenges of the LEAP programme in the Wa West District. The difference-in-difference approach was used to compare the extent to which poverty in the district has been alleviated among beneficiaries of the LEAP programme vis-à-vis non-beneficiaries. The Difference-in-difference approach is a statistical method usually used in econometrics and research. It seeks to appraise the impact or effects of a programme on an outcome, say $X$, over a selected population of people. Two groups are observed, a 'treatment group' and a 'control group'. While the 'treatment group' is subjected to a treatment, the 'control group' is not exposed to any treatment. The effects of the treatment are then calculated by using a comparison of any changes in outcome for variables 
in the 'control group' against that of the 'treatment group' over the period of the research. The before and after outcomes are then compared to arrive at a conclusion.

The study will also employ both the quantitative and qualitative approach in conducting this research. According to Bryman (2015) the use of both qualitative and quantitative approaches within a single project is a mixed-method research. A notable advantage of mixed-method research is the completeness and broad portrait it offers through data analysis. Therefore, incorporating qualitative and quantitative methods makes it suitable to handle the multiple dimensions of the study topic. The population of this study is the people of the Wa West district. A sample of 22 beneficiary households and 27 non-beneficiary households of the LEAP programme was used. The instrument used for data collection was the questionnaire. The reason for using a questionnaire is that it provides a quick way of collecting data from the respondents. Questionnaire relates to a form or document containing a number of questions on a particular theme, problem, issue or opinion to be investigated (Kumekpor, 2002). There were two sets of questionnaires, one set for the LEAP beneficiaries and non-beneficiaries and the other set for the implementers of the LEAP programme in the district. The researcher visited the selected households in the communities to administer the questionnaires. For respondents who were not able to read and write in English an effort was made to translate to facilitate the completion of the questionnaire. The respondents were briefed on how to respond to the items and they were given the opportunity to ask questions or to call the researcher to clarify difficulties they may come across in the course of responding to the questions. The data gathered was entered onto the Statistical Package for Social Sciences (SPSS) software. All the analysis of quantitative data was done using the SPSS software. Descriptive summary statistics such as frequencies, percentages, means, and standard deviation was used. The qualitative responses were arranged in general categories to identify common themes to make inferences from each theme and draw conclusions with the data from the quantitative section. The data was analyzed using t-test and Pearson Chi-Square to establish the statistical difference between means and the statistical significance of the relationship between the treatment and comparison groups. A comparative analysis was performed using the "difference-in-difference" scenario (beneficiary and non-beneficiary households). This method gave us a comparative analysis in terms of the similarities and differences between beneficiaries and non-beneficiaries of the LEAP programme. The difference-in-difference statistical approach was used to find the average treatment effects of the LEAP programme. This approach involves calculating the change between a baseline and post intervention for treatment and comparison groups. Table 1 shows how the difference-in-difference approach is calculated.

The baseline and post-intervention values are represented by the top row and the last cell in the top row shows the difference in the value of the outcome of the treatment group. The second row shows the value of the baseline and post-intervention comparison group with the last cell in the second row representing the difference in the value of the outcome of the comparison group. The last cell in the third row represents the difference-in-difference or the double difference estimator between the treatment group and the comparison group. 
Table 1. The difference-in-differences approach

\begin{tabular}{lllll}
\hline & \multicolumn{2}{l}{ Baseline (2013) } & Post (2014) & 1st difference \\
\hline Treatment (T) & (T) 2013 & (T) 2014 & $\Delta \mathrm{T}=(\mathrm{T} 2014-\mathrm{T} 2013)$ \\
Comparison (C) & (C) $\quad \mathrm{C} 2013$ & (C) 2014 & $\Delta \mathrm{C}=(\mathrm{C} 2014-\mathrm{C} 2013)$ \\
& & & Difference-in-differences \\
& & & $\mathrm{DD}=(\Delta \mathrm{T}-\Delta \mathrm{C})$ \\
\hline
\end{tabular}

Source: Imbens et al. (2009).

\section{Findings}

Table 1.1: Demographic statistics of household respondents

\begin{tabular}{llll}
\hline Demography & & Beneficiary & Non-Beneficiary \\
\hline \multirow{5}{*}{ Age Group } & $18-25$ & $20(13.3 \%)$ & $18(12 \%)$ \\
& $26-35$ & $29(19.3 \%)$ & $30(20 \%)$ \\
& $36-45$ & $52(34.7 \%)$ & $51(34 \%)$ \\
& $46-55$ & $35(23.3 \%)$ & $36(24 \%)$ \\
Gender & 56 and above & $14(9.3 \%)$ & $15(10 \%)$ \\
\hline \multirow{5}{*}{ Marital Status } & Male & $72(48 \%)$ & $78(52 \%)$ \\
& Female & $78(52 \%)$ & $72(48 \%)$ \\
\hline \multirow{5}{*}{ Occupation } & Married & $68(45.3 \%)$ & $67(44.7 \%)$ \\
& Never Married & $13(8.7 \%)$ & $15(10 \%)$ \\
& Divorced & $41(27.3 \%)$ & $43(28.7 \%)$ \\
& Widowed & $28(18.7 \%)$ & $25(16.7 \%)$ \\
\hline \multirow{5}{*}{ Level of Education } & Farmer & $67(44.7 \%)$ & $66(44 \%)$ \\
& Trader & $32(21.3 \%)$ & $33(22 \%)$ \\
& Fishermen & $19(12.7 \%)$ & $17(11.3 \%)$ \\
& Unemployed & $32(21.3)$ & $33(22 \%)$ \\
\hline \multirow{5}{*}{ No. of Dependents } & Primary/JHS & $68(45.3)$ & $69(46 \%)$ \\
& Sec/Vocational & $34(22.7)$ & $34(22.7 \%)$ \\
& Tertiary & $12(13.3)$ & $11(13.3 \%)$ \\
& No formal education & $36(24 \%)$ & $36(24 \%)$ \\
\hline & $1-2$ & $31(20.7 \%)$ & $30(20 \%)$ \\
& $3-4$ & $36(24 \%)$ & $36(24 \%)$ \\
& $4-5$ & $49(32.7 \%)$ & $39(32.7 \%)$ \\
& More than 5 & $34(22.7)$ &
\end{tabular}

The ages of respondents (both beneficiary and non-beneficiary households) range from 18 years and over. This age category was chosen because the LEAP programme mainly focuses on empowering the vulnerable, excluded and particularly the aged in the society. The results show that for beneficiary respondents ( 22 households), $70 \%$ were in the age group 36 years 
and over. Similarly, for the non-beneficiary group (27 households), $71.1 \%$ were in the age group 36 years and over. This result shows that majority of beneficiaries and non-beneficiaries of the programme were older people from 36 years and over which is expected since the target group for the programme were people with higher age limits. Of the 22 beneficiary households, 17 household heads were male while 5 were female. 20 of the non-beneficiary household heads were male while the 7 were female. The sex distribution of respondents is presented in column 2. A total of 296 respondents (22 LEAP beneficiary households and 27 non-beneficiary households) were used in this study. The result shows that $31.1 \%$ of the beneficiary groups were males and $68.9 \%$ were females. The results also show that majority of non-beneficiaries were females as $70.45 \%$ of non-beneficiaries were females and $29.55 \%$ were males. This result confirms that majority of beneficiaries and non-beneficiaries are female.

The marital status as indicated by the result shows that, for both beneficiaries and non-beneficiaries $42.7 \%$ and $43.1 \%$ respectfully are married and only $11.6 \%$ of beneficiaries were never married. $18.9 \%$ of non-beneficiaries were never married too. This result shows many respondents are married whereas few of the respondents have never married. On the occupation of respondents, the findings established that $40.8 \%$ of beneficiaries were farmers while $42.4 \%$ of non-respondents were farmers. This was followed by traders and the unemployed. For traders, $19.5 \%$ were beneficiaries and $21.2 \%$ were non-beneficiaries. For fishermen, $15.9 \%$ of beneficiaries were fishermen and $12.8 \%$ of non-beneficiaries were fishermen. Furthermore, $23.7 \%$ of beneficiaries were unemployed whiles $23.5 \%$ of non-beneficiaries were unemployed. The results have shown that despite the fact that a good number of respondents are employed; the total number of unemployed is still high in the Wa West district. This information is illustrated in the table. On the educational levels of respondents, the result shows a majority of both beneficiaries and non-beneficiaries generally had either primary or JHS level of education. On the number of dependents of respondents, the result shows that $32.9 \%$ of beneficiaries had $4-5$ dependents whiles $29.5 \%$ of non-beneficiaries had 4-5 dependents. The result also shows that $25 \%$ of beneficiaries had 3-4 dependents and $24.2 \%$ of the non-beneficiary group had 3-4 dependents. This results thus indicates that majority of respondents have a lot of dependents putting a lot of financial responsibility on them.

\subsection{The Effect of Direct Cash Transfer on Welfare and Poverty Reduction}

To establish the effect of direct cash transfer on welfare and poverty reduction, respondents were asked questions relating to the effect of the LEAP programme on their welfare as well as poverty reduction in the study area. The results are as follows;

\subsection{LEAP Beneficiary Groups}

The results show that, many of the beneficiaries belong to the farmer and fisher folk group as $41 \%$ of beneficiaries fall under that category. This was closely followed by the unemployed and less than 60 years beneficiary group who recorded $23 \%$. Only $10 \%$ and $11 \%$ of beneficiaries belong to the unemployed and over 60 years and disabled group respectively. 


\section{Macrothink}

This results show that majority of beneficiaries of the LEAP programme in the Wa West district are farmers, fishermen and the unemployed under 60 years of age.

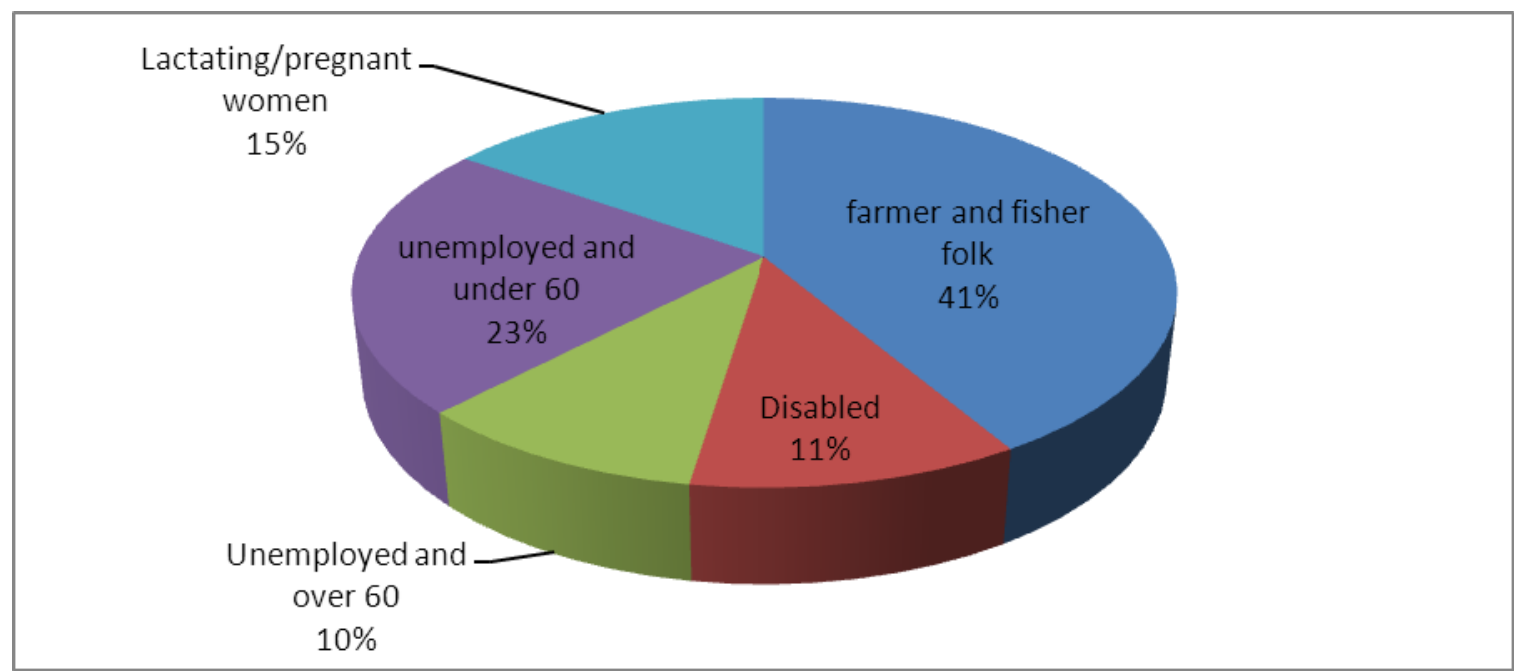

Figure 1.0: LEAP Beneficiary Groups

On the amount of money beneficiaries received at the end of every month from the programme, the results indicate that many of the beneficiaries receive GH\$2 at 43\%, 27\% of beneficiaries received GH\$25, 21\% receive GH\$30 and only 9\% receive more than GH\$30. The results thus show that majority of LEAP beneficiaries receive less than GHष30.

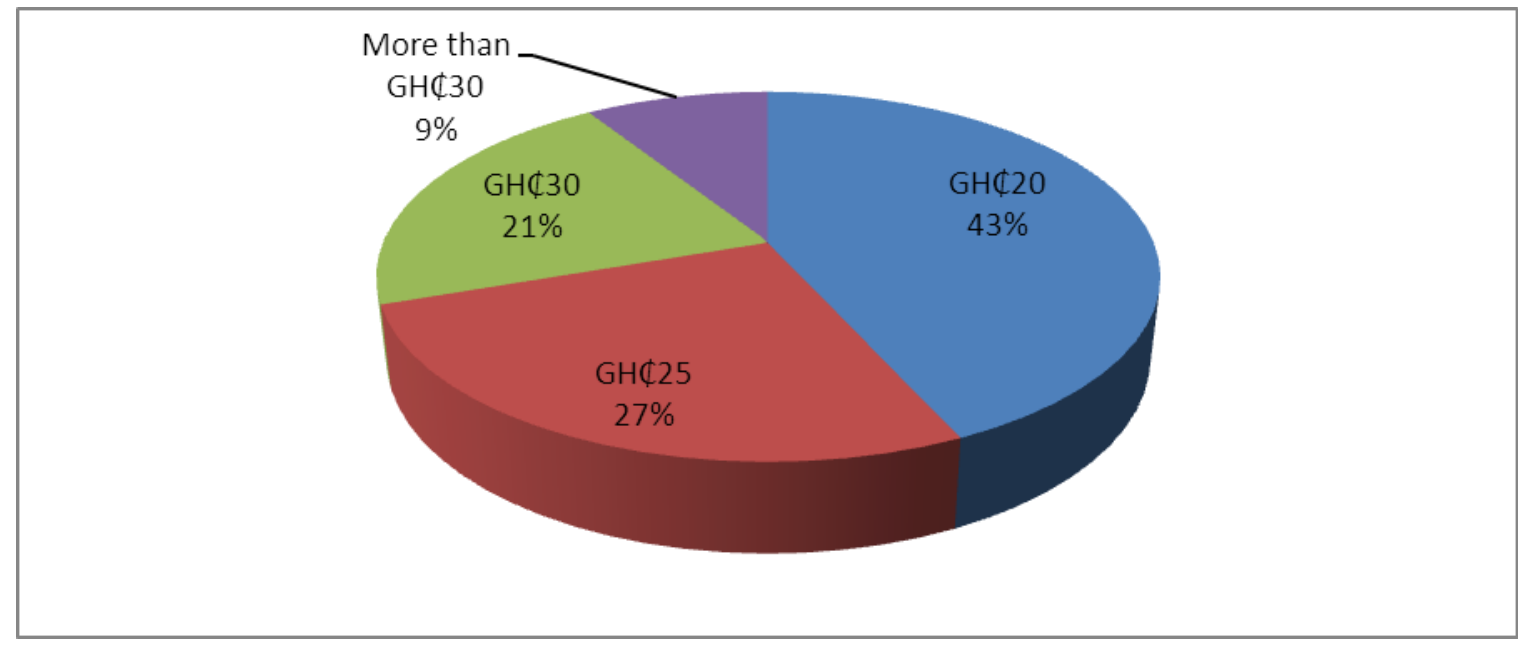

Figure 1.1: Monthly Cash Transfers

\subsection{Frequency of Utilization of Healthcare Facilities}

The impact of the LEAP programme on health care in the Wa West district was measured by the frequency of utilization of healthcare facilities by respondents (both beneficiaries and 
non-beneficiaries) from 2013 to 2014. It is generally expected that, by receiving monthly cash transfers, beneficiaries will be better placed to either get enrolled or afford the minimum cost of enrolling in the NHIS or be better placed to afford healthcare generally especially out of pocket expenditure on healthcare. Beneficiaries are therefore expected to utilize healthcare facilities than non-beneficiaries. The Tables present the frequency of utilization of healthcare facilities and the difference-in-difference between beneficiaries and non-beneficiaries of the cash transfers.

On the part of beneficiaries of the programme, $87.2 \%$ visited health facilities 3 times or more with only $12.8 \%$ not visiting health facilities. For the non-beneficiaries, $55.3 \%$ visited health facilities 1-2 times whiles $44.7 \%$ visited health facilities 3 times or more. This result has therefore shown that majority of beneficiary respondents visited health facilities more than their non-beneficiary counterparts. This result is expected because, as part of the programme, beneficiaries receive free enrolment onto the NHIS which may account for their frequent visits to health facilities. This result is supported by a study by Agbaam and Dinbabo (2014) who found that, the LEAP grant has an impact on the frequency of utilization of healthcare facilities. They found that, the LEAP grant enables access to and use of healthcare services for the poor and can therefore be considered as a major relieve especially in times of sickness. According to them, the fact that beneficiaries spend part of the grant as registration for health insurance or paying for health care related expenditures shows that the poor themselves appreciate the essence of the grant and thus invest it into safeguarding or minimizing the financial barriers associated with the risk of ill health.

Table 1.2: Frequency of Utilization of healthcare facilities

\begin{tabular}{lllll}
\hline \multirow{2}{*}{$\begin{array}{l}\text { Number of times of visits } \\
\text { to Health facilities }\end{array}$} & \multicolumn{2}{c}{ Beneficiaries } & \multicolumn{2}{c}{ Non-Beneficiaries } \\
\cline { 2 - 5 } & $\begin{array}{l}\text { Number of } \\
\text { Beneficiaries }\end{array}$ & Percentage & $\begin{array}{l}\text { Number of } \\
\text { Non-Beneficiaries }\end{array}$ & Percentage \\
\hline 1-2 Times & $\mathbf{2 1}$ & 12.8 & 73 & 55.3 \\
3-4 Times & $\mathbf{4 9}$ & 29.8 & 26 & 19.7 \\
4-5 Times & $\mathbf{5 8}$ & 35.4 & 15 & 11.4 \\
More than 6 Times & $\mathbf{3 6}$ & 22.0 & 18 & 13.6 \\
Total & 164 & 100 & 132 & 100 \\
\hline
\end{tabular}




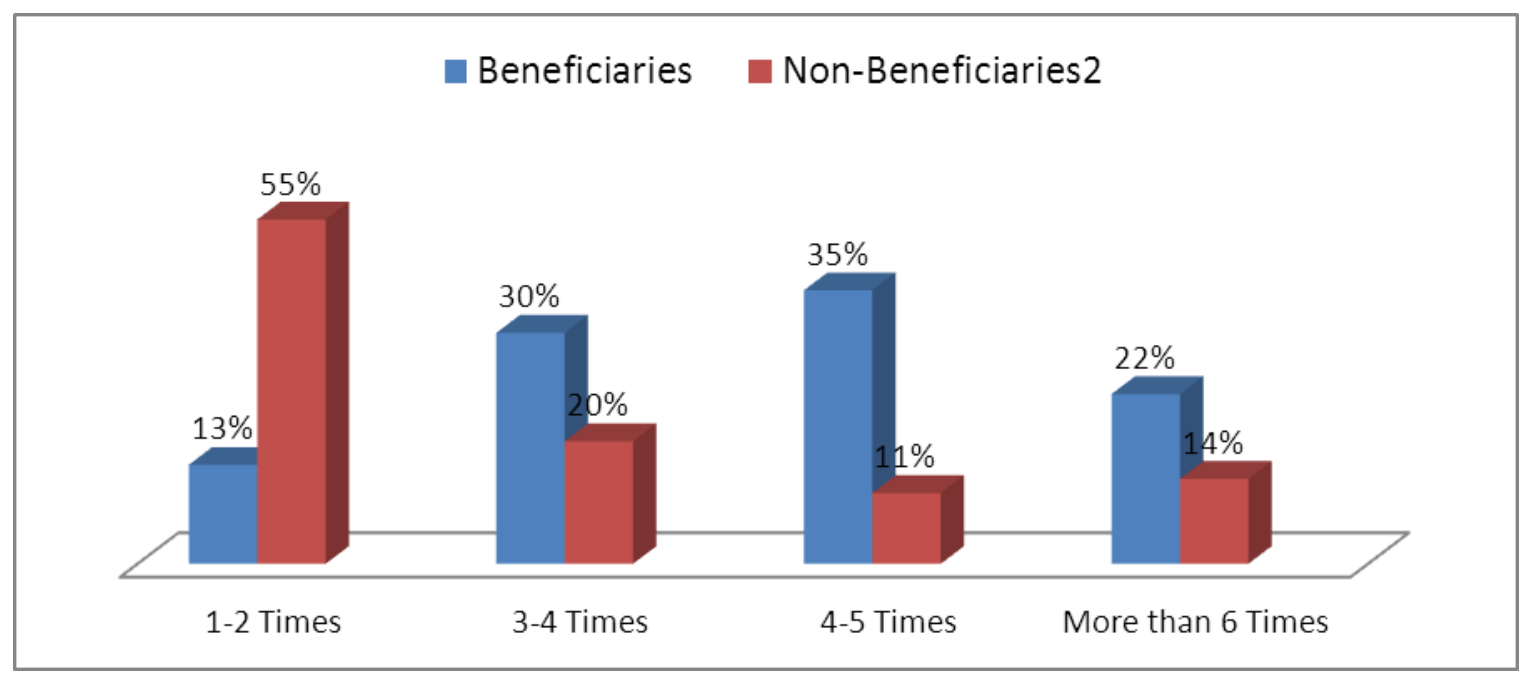

Figure 1.2: Numbers of visits to health facilities

According to the LEAP programme, beneficiaries are supposed to be enrolled automatically onto the NHIS through an arrangement with the Ministry of Health. This aspect of the programme has significant impact on NHIS enrolment rate as $90 \%$ of beneficiaries were enrolled onto the NHIS as indicated in table below. On the other hand, the increase in NHIS in the non-beneficiary group was only 19 percent; hence there was a net increase of 34 percent (the difference-in-differences or DD) in terms of the enrolment rate of the NHIS. This difference is also statistically significant meaning that, the LEAP programme has ensured that majority of people in the study area are enrolled onto the NHIS.

Table 1.3: Enrollment in NHIS by sample and year (\%)

\begin{tabular}{llll}
\hline Year & $\mathbf{2 0 1 3}$ & $\mathbf{2 0 1 4}$ & $\mathbf{1}^{\text {st }}$ Difference \\
\hline LEAP & 37 & 90 & 53 \\
Comparison Group & 28 & 47 & 19 \\
& & & DID $=34$ \\
\hline
\end{tabular}

\section{Household Food Security}

To establish the impact of the LEAP programme on food security in the study area, respondents were asked whether or not they were food-secured. By receiving cash transfers, it is expected that beneficiaries of the LEAP programme will be more satisfied after meals than non-beneficiaries. The Table below presents results from food consumption by LEAP and/or non-LEAP status in the study area. The result indicates that majority $(64.6 \%)$ of beneficiaries of the LEAP programme were satisfied with their food consumption whiles $(60.6 \%)$ of non-beneficiaries were not satisfied with their food consumption. To ascertain 
whether this conclusion is valid or not, we employed the Pearson Chi-Square test to test whether there is a correlation between the satisfaction of meals and LEAP status.

Table 1.4: Household food security

\begin{tabular}{ccc}
\hline & Beneficiaries & Non-Beneficiaries \\
\hline $\begin{array}{c}\text { Food satisfaction } \\
\text { Satisfied }\end{array}$ & $106(64.6 \%)$ & $\mathbf{5 2 ( 3 9 . 4 \% )}$ \\
Not Satisfied & $58(35.4 \%)$ & $\mathbf{8 0}(\mathbf{6 0 . 6 \%})$ \\
\hline TOTAL & $\mathbf{1 6 4 ( \mathbf { 1 0 0 \% } )}$ & $\mathbf{1 3 2 ( \mathbf { 1 0 0 \% } )}$ \\
& & \\
Chi-Square $=\mathbf{5 5 . 6}$ & P-Value $=\mathbf{0 . 0 0 0}$ & \\
\hline
\end{tabular}

The result of the Pearson Chi-Square shows a Chi-Square value of 55.6 and a p-value of 0.000 which indicates that, there exist a statistically significant relationship between satisfaction of meals and LEAP status and that beneficiaries of the LEAP programme get more satisfied after meals than non-beneficiaries of the programme. This result is confirmed by a cross-country study done by Barrientos (2005) who demonstrated that, there exist a positive impact of cash transfers for increasing per capita consumption and reducing the poverty gap.

Table 1.5: Food consumption by sample and year (\%)

\begin{tabular}{llll}
\hline Year & 2013 & 2014 & $1^{\text {st }}$ Difference \\
\hline LEAP & 32 & 84 & 52 \\
Comparison Group & 33 & 48 & 15 \\
& & & DID $=37$ \\
\hline
\end{tabular}

On access to credit and loans, the result shows that majority of beneficiaries of the LEAP programme had greater access to credit and loans than non-beneficiaries of the LEAP programme. The result in the following table shows that $68.9 \%$ of beneficiaries had access to credit whiles $41 \%$ of non-beneficiaries had access to credit. This may be as a result of the fact that beneficiaries of the LEAP programme will be better placed to repay loans as a result of the a monthly flow of cash transfers as compared to non-beneficiaries. However, to ascertain whether there is a statistical difference between the mean of the beneficiary group and non-beneficiary group in terms of access to credit and loans, the t-test was employed.

The results of the t-test show a t-value of (7.32) and a p-value of (.000). Since the significance value is less than the significance level of $5 \%$, we conclude that there exists a significant difference between the mean of the beneficiary group and non-beneficiary group and that access to credit amongst the beneficiary group is significantly higher than the non-beneficiary group. 
According to Essuman and Bosumtwi-Sam (2013), the LEAP transfer helped reduce the amount of borrowing and financial risk and asset disinvestment amongst beneficiary households while increasing their capacity to cope on a day-to-day basis through risk-averse coping strategies. There is the less likely possibility that LEAP households would be indebted (borrowing money from extended family) as a result of survival consequences. Linkages to micro-credit, the FAO contends, through the Ministry of Women and Children's Affairs (MOWAC) is also an envisaged complementary service (Essuman \& Bosumtwi-Sam, 2013).

Table 1.6: Access to credit by LEAP status

\begin{tabular}{ccc}
\hline & LEAP STATUS \\
\hline Access to credit & Beneficiaries & Non-Beneficiaries \\
Yes & $113(68.9 \%)$ & $\mathbf{5 4}(\mathbf{4 1 \% )})$ \\
No & $51(31 \%)$ & $\mathbf{7 8 ~ ( 5 9 \% )}$ \\
\hline Total & $\mathbf{1 6 4}(\mathbf{1 0 0 \% )}$ & $\mathbf{1 3 2}(\mathbf{1 0 0 \% )}$ \\
\hline
\end{tabular}

\section{The challenges of the LEAP programme in the Wa District}

To find out some of the key challenges of the LEAP programme in the study area, the views of respondents were sought. The first challenge of the LEAP programme according to many respondents is the fact that the monthly cash transfers was too low making it difficult for beneficiaries to cover their basic needs. According to respondents, as a result of the low monthly cash transfers, most of the beneficiaries still depend on other family and community members to be able to meet their basic needs. The second challenge of the LEAP programme according to $78 \%$ of respondents was that, the payment of transfers was not regular as sometimes it took three to five months to receive the transfers. As a result of this situation, some beneficiaries had to look for other sources of generating income especially engaging their young children in commercial activities to supplement the family income. The first and second views of respondents are supported by Dercon (2006) who found that social cash transfers can enable the poor to protect themselves and their assets against shocks, thereby, enabling them to defend their long-term income-generating potential only if such transfers are regular and adequate. The complex processes one has to go through to become a beneficiary as well as the cumbersome process of collecting the cash was also cited as one of the key challenges of the LEAP programme. This according to the respondents makes the implementation of the LEAP programme very difficult and the objective of the programme might not be achieved if the situation is not improved. Furthermore, the difficulty in assessing some automatic benefits notably NHIS was mentioned as one of the key challenges of the LEAP programme. In fact, some respondents indicated that they often find it extremely difficult either enrolling onto the NHIS or renewing NHIS cards. Finally, respondents perceive corruption in the implementation of the LEAP programme. Some respondents indicated that some beneficiaries are favored than others especially in the payment of cash 
transfers. Other respondents also mentioned that they sometimes receive cash transfers lower than what they are expected to get.

\section{Conclusion}

The main objective of the study was to ascertain the extent to which the LEAP has improved welfare and reduced poverty in the Wa West District. The results revealed that majority of LEAP beneficiaries visit health facilities as compared to the non-beneficiaries. The study further revealed that, the LEAP programme had positive impact on food security as LEAP beneficiaries were more satisfied in terms of food consumption as compared to non-beneficiaries. On the effect of the LEAP programme on access to credit, the study revealed that there exist a significant difference between the mean of the beneficiary group and non-beneficiary group and that access to credit amongst the beneficiary group is significantly higher than the non-beneficiary group. The second research question was to find out the challenges of the LEAP programme in the Wa West District. The study revealed that among the challenges of the LEAP programme were low monthly cash transfers, irregular and delayed payment of transfer, cumbersome registration process and difficulty in assessing some automatic benefits notably NHIS. The fifth and final challenge enumerated by respondents was the perception of corruption in the implementation of the LEAP programme. On the part of staff members of the LEAP programme, lack of logistics, limited or no refresher courses, limited personnel were key problems. Finally, staff members of the LEAP programme believe the programme has had positive impact on poverty reduction especially on education and healthcare in the Wa West District.

Based on the findings, the study concludes that the implementation of the LEAP programme has had a significant positive impact on education, health and food consumption in the Wa West district. The study also concludes that access to credit amongst LEAP beneficiary group is significantly higher than the non-beneficiary group. The study recommends an increase in the amount of cash transferred to beneficiaries to enable beneficiary households meet their basic needs. Even though constrained by financial resources, this proposal is highly recommended. It is further recommended that the cash transfers be paid regularly and delays in the payment of transfers be eliminated. The study also recommends transparency in the registration and distribution of cash transfers to reduce the perception of corruption. The study further recommends the recruitment of qualified staff members and regular training for staff members. It is also recommended that within the arrangement of support for a successful LEAP programme there is a need to reconsider the functionality and efficiency of the District LEAP Implementation Committee (DLIC) and the Community LEAP Implementation Committee (CLIC). There is the need for resources to be made available to support monitoring and support activities and sustain interest in the programme. The study also recommends that government's poverty alleviation programmes should be backed by and supported with comprehensive public enlightenment programmes at the rural areas, so as to draw the people to the programme. The government should increase the number of participants in the LEAP scheme to cover more eligible people. The number of farmers who are also in the scheme should be increased by tailoring specific schemes that take into consideration the nature of the business to enable them put more land into cultivation. In this 
regard, local authorities and other non-governmental organizations could collaborate to give more training on business management to the participants to enable them apply the cash benefit to their business to result in their expansion which would ultimately lead to improved businesses and well-being for the households.

\section{References}

Abebrese, J. (2011). Social Protection in Ghana: An overview of existing programmes and their prospects and challenges. Friedrich Ebert Stiftung.

Agbaam, C., \& Dinbabo, M. F. (2014). Social Grants and Poverty Reduction at the Household Level: Empirical Evidence from Ghana. J Soc Sci, 39(3), 293-302.

Arvind, S., \& Devesh, R. (2003). Who can Explain the Mauritian Miracle: Meade, Romer, Sachs, or Rodrik. Rodrik, ed., In Search of Prosperity: Analytic Narratives on Economic Growth.

Barrientos, A. (2005). Non-contributory pensions and poverty reduction in Brazil and South Africa. IDPM, University of Manchester.

Bryman, A. (2015). Social research methods: Oxford university press.

Cornia, G. A. (2014). Falling Inequality in Latin America: Policy Changes and Lessons: OUP Oxford.

Currie, J., \& Gahvari, F. (2007). Transfers in cash and in kind: theory meets the data. Retrieved from

Dercon, S. (2006). Vulnerability: a micro perspective. Securing development in an unstable world, 30, 117-146.

Devereux, S., \& Coll-Black, S. (2007). Review of evidence and evidence gaps on the effectiveness and impacts of DFID-supported pilot social transfer schemes. DFID Social Transfers Evaluation.

DFID, U. (2005). Social transfers and chronic poverty: emerging evidence and the challenge ahead. DFID Report. London.

Essuman, A., \& Bosumtwi-Sam, C. (2013). School feeding and educational access in rural Ghana: Is poor targeting and delivery limiting impact? International Journal of Educational Development, 33(3), 253-262. http://dx.doi.org/10.1016/j.ijedudev.2012.09.011

FAO, V. (2004). Voluntary guidelines to support the progressive realization of the right to adequate food in the context of national food security: Rome.

Fernald, L. C. H. Promise, and risks, of conditional cash transfer programmes. The Lancet, 382(9886), 7-9. doi:10.1016/S0140-6736(13)61035-1

Fiszbein, A., Schady, N. R., \& Ferreira, F. H. (2009). Conditional cash transfers: reducing present and future poverty: World Bank Publications. 
GSS. (2014). Ghana Living Standards Survey. Accra, Ghana.

Handa, S., \& Stewart, S. (2008). The orphan targeting dilemma in Eastern and Southern Africa. Poverty in focus(15).

Joha, B. I. (2012). Effects of LEAP on Poverty Reduction of Beneficiary Households in Yama, Northern Region. University of Ghana.

Kaldor, N. (1955). Alternative Theories of Distribution. The Review of Economic Studies, 23(2), 83-100. Retrieved from http://www.jstor.org/stable/2296292

Kapur, A., \& Duvvury, N. (2006). A rights-based approach to realizing the economic and social rights of poor and marginalized women. A synthesis of lessons learned.

Kent, G. (2015). Ending hunger worldwide: Routledge.

Khor, M. (2003). The IMF's role and policy conditionality: The relationship between ownership, conditionality, appropriateness of policy and governance, and the way forward. Deutsche Stiftung für internationale Entwicklung, Berlin (http://www.dse. delef/cond/khor $2 / \mathrm{htm}$ ).

Kumekpor, T. K. (2002). Research methods and techniques of social research: SonLife Press $\&$ Services.

Künnemann, R., \& Leonhard, R. (2008). A human rights view on the potential of social cash transfers for achieving the millennium development goals. Brot für die Welt and Evangelischer Entwicklungsdienst.

Nyamu-Musembi, C., \& Cornwall, A. (2004). What is the" rights-based approach" all about?: perspectives from international development agencies.

Ribas, R., Soares, V. V., \& Hirata, G. (2008). The Impact of CCTs: What we know and what we are not sure about. Poverty in focus, 15, 12-13.

Samson, M. (2006). Designing and implementing social transfer programmes: EPRI Press.

Samson, M., Lee, U., Ndlebe, A., MacQuene, K., van Niekerk, I., Gandhi, V., . . A Abrahams, C. (2004). The Social and Economic Impact of South Africa's Social Security System: Final Report: Economic Policy Research Institute.

Sulzbach, S., Garshong, B., \& Banahene, G. (2005). Evaluating the Effects of the National Health Insurance Act in Ghana. Baseline Report. The Partners for Health Reformplus Project, Abt Associates Inc., Bethesda, MD.

Vincent, K., \& Cull, T. (2009). Impacts of social cash transfers: case study evidence from across southern Africa. II Conferenciado IESE "Dinamicas da PobrezaePadrões de Acumulaçãoem Moçambique”, Maputo, 22 e 23 de Abril de 2009.

Williams, M. J. (2007). The social and economic impacts of South Africa's child support grant. WILLIAMS COLLEGE. 


\section{Macrothink}

International Journal of Social Science Research

ISSN 2327-5510

2016, Vol. 4, No. 2

Yaro, J. A. (2004). Theorizing food insecurity: building a livelihood vulnerability framework for researching food insecurity. Norsk Geografisk Tidsskrift-Norwegian Journal of Geography, 58(1), 23-37.

\section{Copyright Disclaimer}

Copyright for this article is retained by the author(s), with first publication rights granted to the journal.

This is an open-access article distributed under the terms and conditions of the Creative Commons Attribution license (http://creativecommons.org/licenses/by/3.0/). 